\title{
Activated and Nonactivated Date Pits Adsorbents for the Removal of Copper(II) and Cadmium(II) from Aqueous Solutions
}

\author{
Nora M. Hilal, ${ }^{1}$ Inas A. Ahmed, ${ }^{2}$ and Ragaa E. El-Sayed ${ }^{1}$ \\ ${ }^{1}$ Chemistry Department, Faculty of Science, Al-Azhar University (Girls), Nasr City, Cairo, Egypt \\ ${ }^{2}$ Faculty of Science, Zagazig University, Zagazig, Egypt
}

Correspondence should be addressed to Nora M. Hilal, aliata1966@yahoo.com

Received 12 October 2012; Accepted 31 October 2012

Academic Editors: T. Panczyk, S. Sasaki, and D. Strout

Copyright (C) 2012 Nora M. Hilal et al. This is an open access article distributed under the Creative Commons Attribution License, which permits unrestricted use, distribution, and reproduction in any medium, provided the original work is properly cited.

\begin{abstract}
The present study aims to investigate the adsorption behavior of $\mathrm{Cu}(\mathrm{II})$ and $\mathrm{Cd}(\mathrm{II})$ ions from wastewater onto low-cost adsorbents either raw date pits (RDP), cheap agricultural and nontoxic materials, or chemically activated carbon (ADP) prepared by modified date pits using phosphoric acid. A series of experiments were conducted in a batch system to evaluate the effect of system variables. The adsorption process is affected by various parameters such as solution $\mathrm{pH}$, contact time, initial concentrations of metals, and adsorbent dose. The optimum $\mathrm{pH}$ required for maximum adsorption was found to be $5.8 \pm 0.5$. The experimental data were tested using Langmuir, Freundlich, Dubinin-Radushkevich (D-R) isotherm equations. It was observed that the adsorption capacity of date pits increased after treatment with phosphoric acid. The maximum uptake capacities $\left(Q_{m}\right)$ were 7.40 and $33.44 \mathrm{mg}$ copper(II) per gram of RDP and ADP, respectively, while 6.02 and $17.24 \mathrm{mg}$ cadmium(II) per gram of RDP and ADP, respectively. The results showed that although the equilibrium data could be described by the three models used, Langmuir model gave slightly better results while Freundlich model gave better results when using raw and activated date pits.
\end{abstract}

\section{Introduction}

Contamination of aqueous environments by toxic heavy metals through the discharge of industrial wastewater is a particularly intractable problem threatening the ecosystem. Rapid industrialization has seriously contributed to the release of toxic heavy metals to water streams [1]. Toxic metal compounds not only contaminate surface water sources (seas, lakes, ponds, and reservoirs), but also contaminate underground water in trace amounts by leaching from the soil after rain and snow [2]. Cd is a nonessential, nonbeneficial, and highly toxic element to plants and animals [3]. Cd is introduced into the water from smelting, metal plating, cadmium-nickel batteries phosphate fertilizers, mining, pigments, stabilizers, alloy industries, and sewage sludge. Cadmium(II) is listed as the sixth most poisonous substance jeopardizing human health. Exposure to lower amounts of cadmium may cause gastrointestinal irritation, vomiting, abdominal pain, and diarrhea. Acute exposure may affect kidneys, resulting in tubular proteinosis and sometimes fatality [4].
Copper is an essential nutrient, required by the body in very small amounts. Short periods of exposure can cause gastrointestinal disturbances, including nausea and vomiting. Use of water that exceeds the permissible level over many years could cause liver or kidney damage. Copper is rarely found in source water, but copper mining and smelting operations and municipal incineration may be sources of contamination [5].

There are several methods to treat the metal contaminated effluent, but the selection of the wastewater treatment methods is based on the concentration of waste and the cost of treatment [6-15]. However, these methods are either inefficient or expensive especially when the concentration of the heavy metal ion is low, in the range of $1-100 \mathrm{mg} / \mathrm{L}$ [16]. This has, therefore, led to the use of agricultural wastes in removal of heavy metals.

Agricultural wastes are characterized by ready availability, affordability, ecofriendliness, and high uptake capacity for heavy metals due to the presence of functional groups which can bind metals to affect the removal of heavy metal from effluents [17]. Adsorption is one of the more popular 
methods for the removal of metals ions from the aqueous solutions. Adsorption is a surface phenomenon, in which molecules of adsorbate are attracted and held to the surface of an adsorbent until an equilibrium is reached between adsorbed molecules and those still freely distributed in the carrying gas or liquid. The adsorption phenomenon depends on the interaction between the surface of the adsorbent and the adsorbed species. The interaction may be due to: (1) chemical bonding; (2) hydrogen bonding; (3) hydrophobic and (4) van der Waals forces [18]. The adsorption isotherms represent the relationship between the amount adsorbed by a unit weight of solid adsorbent and the amount of solute remaining in the solution at equilibrium. Langmuir and Freundlich isotherms models are frequently used isotherm models for describing adsorption of metal ions by different materials.

In the present investigation, raw date pits (RDP) and an activated carbon (ADP) prepared from it have been used as adsorbents for the removal of cadmium(II) and copper(II). The aim of the present work is to explore the possibility of utilizing RDP and ADP for the adsorptive removal of copper(II) and cadmium(II) from wastewater. The effect of such factors as initial $\mathrm{pH}$, adsorbent dose, contact time, and initial concentration was investigated. The kinetics of cadmium(II) and copper(II) adsorption on both adsorbents was analyzed by various kinetic models. Experimental equilibrium data were fitted to the Langmuir, Freundlich, and DubininRadushkevich (D-R) isotherm equations to determine the best-fit isotherm equation. Different error analysis methods were used to determine the isotherm parameters for accurate elucidation of the experimental data.

\section{Material and Methods}

2.1. Adsorbent Preparation. Date pits were collected and washed with hot tap water then by distilled water and allowed to dry in an oven at $80^{\circ} \mathrm{C}$ for 2 hours. The dried samples were crushed and ground by using an electric agitated mortar. The powdered sample was sieved in a sieve series 60-mesh size $(D<125 \mathrm{~nm})$. The sieved date pits were used for batch experiments as raw material (RDP) and as activated carbon (ADP). Date pits powder was mixed with $85 \%$ phosphoric acid in weight ratio $1: 3$, then diluted 5 times with deionized water in a $1000 \mathrm{~mL}$ beaker. The mixture was gently boiled with stirring for few hours until the mixture turned to a black paste. The temperature of the paste at this stage was kept at $160^{\circ} \mathrm{C}$. Primary air activation was carried out during continuous heating while the material stirred for $15 \mathrm{~min}$. During this period of carbonization and activation, the temperature was increased from 160 to $215^{\circ} \mathrm{C}$. This is followed by secondary air activation in which the black paste was heated electrically for $30 \mathrm{~min}$ at a temperature of about $600^{\circ} \mathrm{C}$. After activation, the synthesized carbon was cooled for $10 \mathrm{~min}$ with the tap water, then washed with boiling deionized water the slurry was filtered; the activated carbon date pits (ADP) were dried in an oven at $100^{\circ} \mathrm{C}$ for $12 \mathrm{~h}$, then cooled in desiccators, weighed, grounded, transferred to a container, and stored in the desiccators.
2.2. Adsorbate Preparation. Stock solutions of $1000 \mathrm{mg} / \mathrm{L}$ of $\mathrm{Cd}$ and $\mathrm{Cu}$ ions were prepared by diluting with deionised water. The adsorbate stock solutions containing $\mathrm{Cd}(\mathrm{II})$ and $\mathrm{Cu}(\mathrm{II})$ were prepared from cadmium chloride $\left(\mathrm{CdCl}_{2}\right.$. $\left.2 \mathrm{H}_{2} \mathrm{O}\right)$ and copper chloride $\left(\mathrm{CuCl}_{2} \cdot 6 \mathrm{H}_{2} \mathrm{O}\right)$. All adsorption experiments were carried out using reagent bottles of $250 \mathrm{~mL}$ capacity containing different amounts of each adsorbent in $200 \mathrm{~mL}$ solutions of different concentrations. The $\mathrm{pH}$ of each experimental solution was adjusted to the required initial $\mathrm{pH}$ value using $0.1 \mathrm{~N} \mathrm{HCl}$ or $1 \mathrm{~N} \mathrm{NaOH}$ before mixing the adsorbent.

2.3. Batch Adsorption Studies. Batch experiments were performed at $25 \pm 1^{\circ} \mathrm{C}$ and carried out at various $\mathrm{pH}(2.1-9.05)$, initial concentration of $\mathrm{Cd}(\mathrm{II})$ or $\mathrm{Cu}(\mathrm{II})(10-110 \mathrm{mg} / \mathrm{L})$, adsorbent dose $(0.01-2 \mathrm{~g} / \mathrm{L})$, and stirring speed $(180 \mathrm{rpm})$ for a contact time from 0 to $200 \mathrm{~min}$. For each batch experiment, $200 \mathrm{~mL}$ of $50 \mathrm{mg} / \mathrm{L}$ of two metal ions solution was used. After setting $\mathrm{pH}$ and adding desired amount of adsorbent, the mixture was agitated on mechanical shaker for $45 \mathrm{~min}$. After that the mixture was filtered to separate the adsorbent from supernatant. The residual concentration of both ions was determined by flame atomic spectrometer. All experiments were replicated thrice for all the adsorbents, and results were averaged.

2.4. Analytical Techniques. Atomic absorption spectrophotometer with an air acetylene flame and hollow cathode lamps for $\mathrm{Cu}$ and $\mathrm{Cd}$ was used for metal ions analysis. The pore structure in raw and activated date pits was observed by using scanning electron microscope (SEM).

The removal efficiency percentage (RE\%) of copper and cadmium ions was calculated for each run by the following expression:

$$
\mathrm{RE} \%=\left[\frac{\left(C_{o}-C_{e}\right)}{C_{o}}\right] 100,
$$

where $C_{o}$ and $C_{e}$ are the initial and equilibrium concentrations of both metal ions in the solution. The adsorption capacity of an adsorbent which is obtained from the mass balance on the sorbate in a system with solution volume $V$ is often used to acquire the experimental adsorption isotherms. Under the experimental conditions, the adsorption capacities of all the adsorbents for each concentration of $\mathrm{Cu}$ (II) and $\mathrm{Cd}(\mathrm{II})$ ions at equilibrium were calculated as follows:

$$
q_{e}(\mathrm{mg} / \mathrm{g})=\left(C_{o}-C_{e}\right) \frac{V}{M},
$$

where $C_{o}$ and $C_{e}$ are the initial and equilibrium concentrations of both ions in the solution, respectively. $V$ is the volume of solution $(L)$, and $M$ is the mass of adsorbent (in g) used.

\section{Results and Discussion}

3.1. Characteristics of Adsorbent. A scanning electron microscope (SEM) was used to examine the surface of the raw 


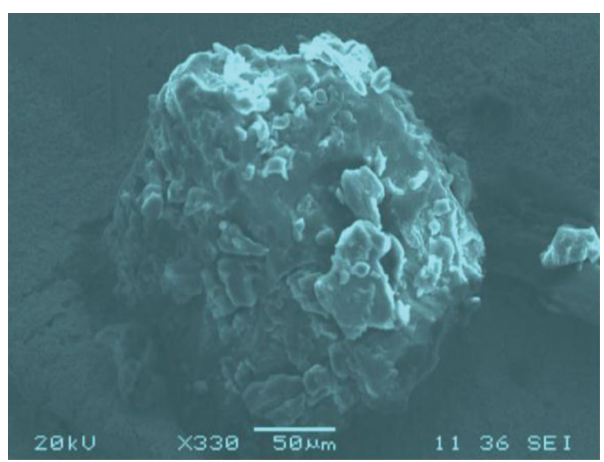

(a)

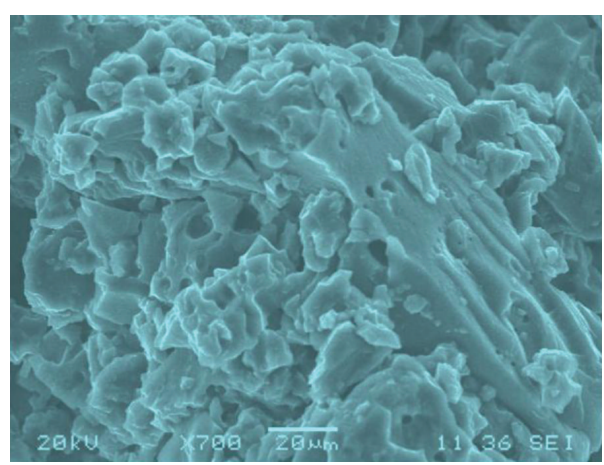

(b)

FIGURE 1: Scanning electron micrographs of (a) raw date pits, RDP and (b) activated carbon of date pits, ADP.

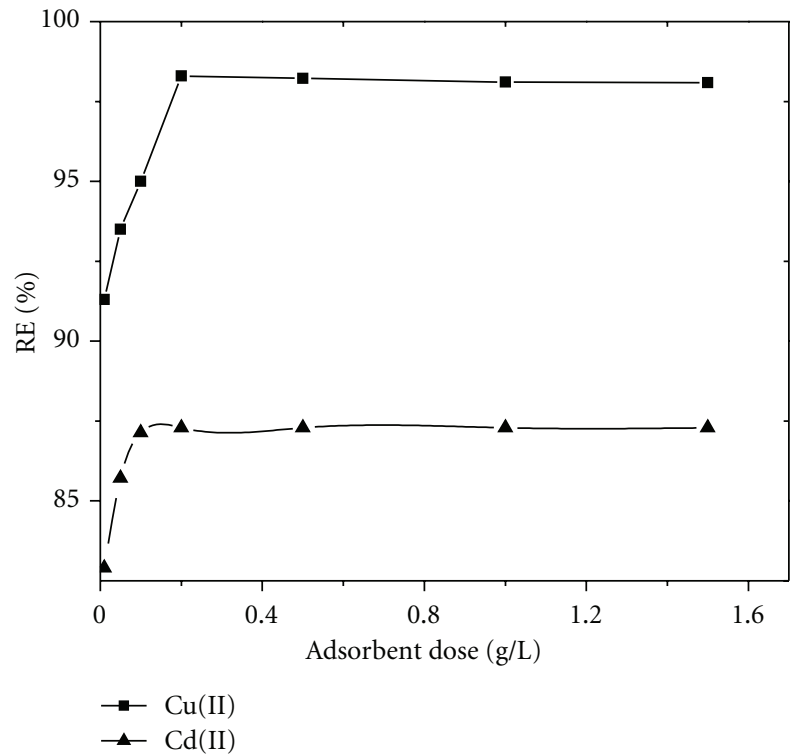

(a)

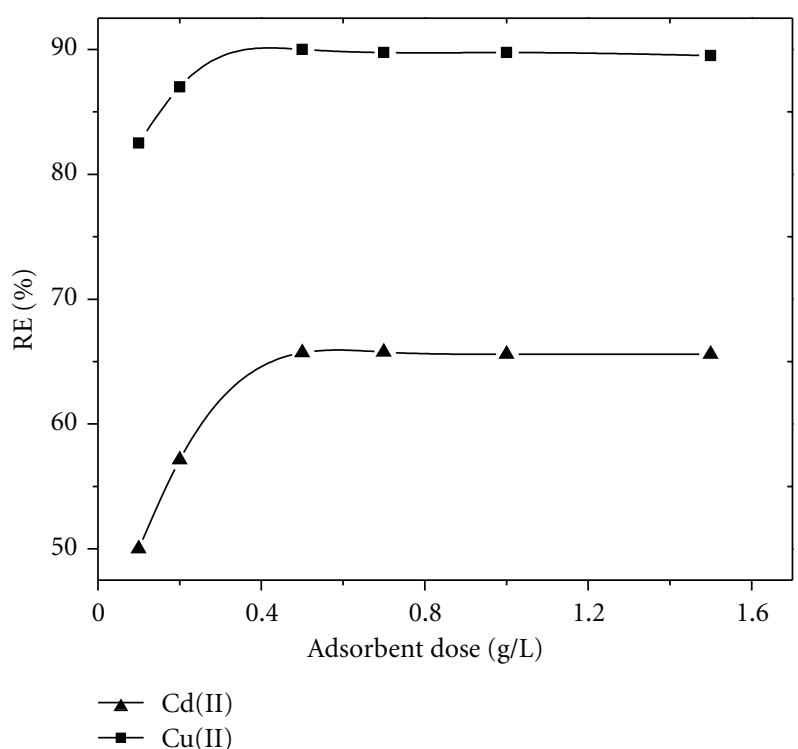

(b)

FIGURE 2: Effect of adsorbent dosage of (a) ADP and (b) RDP on adsorption of Cd(II) and Cu(II).

and activated date pits (RDP and ADP). The SEM image (Figures 1(a) and 1(b)) revealed changes in surface morphology of raw material as it underwent both physical and chemical carbonization. The activated carbon (ADP) showed high porosity compared to raw material (RDP). This was because during carbonization process of raw material with phosphoric acid at high temperature $\left(600^{\circ} \mathrm{C}\right)$, most volatile matter was lost and thus created a system with advanced pore structure. Impregnation with phosphoric acid followed by the second carbonization dehydrated the cellulose material, resulting in weakening of the precursor structure and creation of pores. During chemical activation process, phosphoric acid was responsible for decomposition of organic material to release volatile matter and development of microporous structure which could increase the adsorption capacity [19]. Besides, phosphoric acid was also important in minimizing the formation of tars and other liquids which could clog up the pores and inhibit the development of pores [20]. The porosity created in the carbon structure was also resulted from phosphoric acid removal from carbon structure by intense washing. Pores development in an activated carbon is important since pores act as active sites, playing the main role in adsorption. Pores formed on surface of adsorbent are sites for metals to be adsorbed onto the adsorbent.

3.2. Effect of Adsorbent Dosage. The dosage of adsorbent was a key parameter to control both availability and accessibility of adsorption sites [21]. The effect of adsorbent dosage (0.1$1.5 \mathrm{~g}$ of RDP and $0.01-1.5 \mathrm{~g}$ of ADP) on the removal of $\mathrm{Cu}(\mathrm{II})$ and $\mathrm{Cd}(\mathrm{II})$ ions was presented in Figures 2 (a) and 2(b). The effect of varying doses of RDP and ADP was investigated using $50 \mathrm{mg} / \mathrm{L}$ initial concentration of two metals, at initial pH $5.8 \pm 0.5$ and contact time $60 \mathrm{~min}$.

The results show an increase in removal efficiency percentage of cadmium and copper with the increase in dose of adsorbent up to a certain limit and then it remains almost 


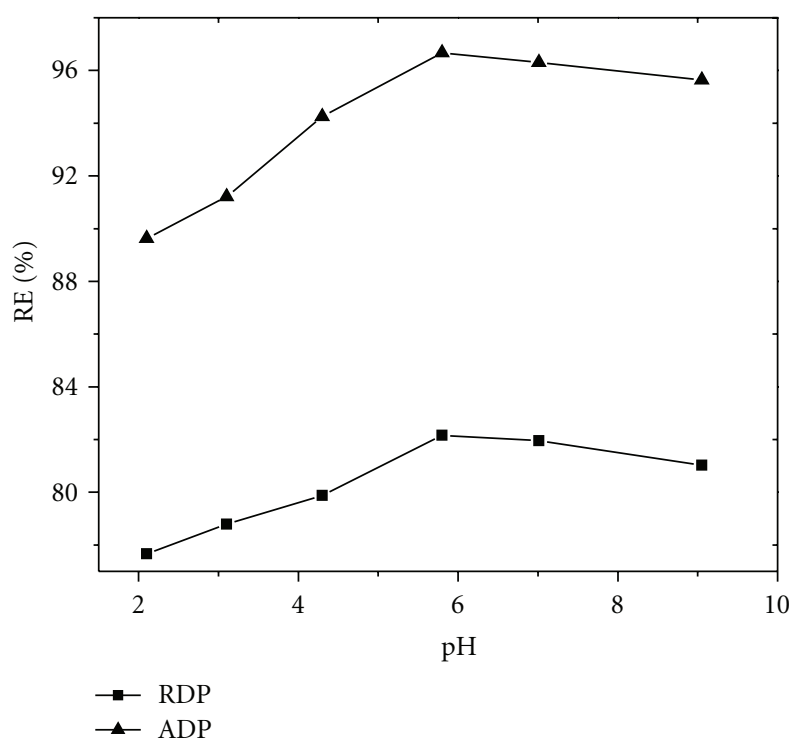

(a)

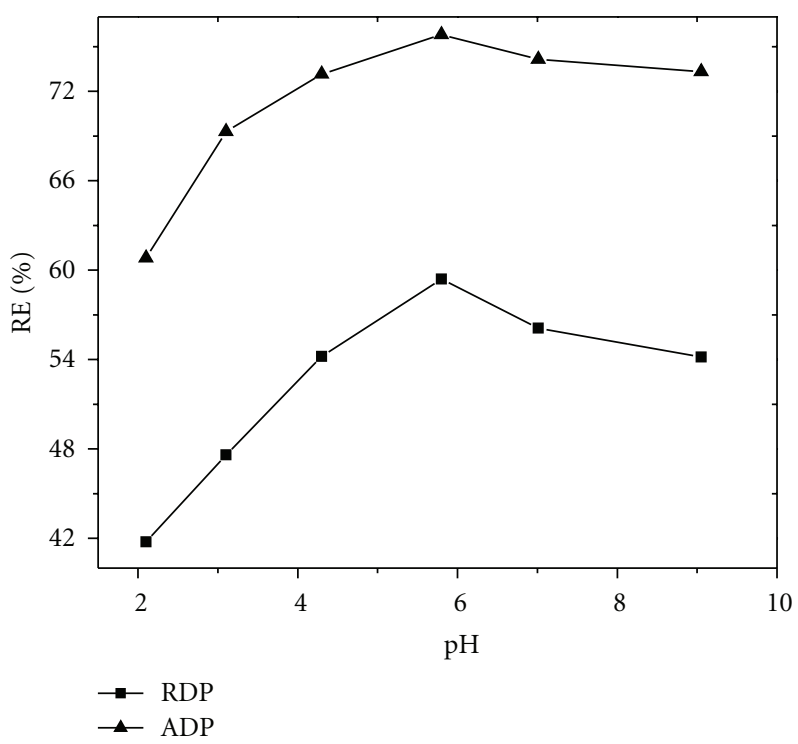

(b)

Figure 3: Effect of $\mathrm{pH}$ on adsorption of (a) $\mathrm{Cu}(\mathrm{II})$ and (b) $\mathrm{Cd}(\mathrm{II})$ onto selected adsorbent at adsorbent dosage (0.5 g RDP and $0.2 \mathrm{~g}$ ADP), initial concentration $50 \mathrm{mg} / \mathrm{L}$.

constant. Increase in the adsorption with increasing dose of adsorbent is expected due to the increase in adsorbent surface area and the availability of more adsorption sites [22]. The relative increase in the percentage removal of $\mathrm{Cu}(\mathrm{II})$ and $\mathrm{Cd}(\mathrm{II})$ ions is found to be insignificant $0.2 \mathrm{~g}$ of ADP and $0.5 \mathrm{~g}$ of RDP, which is fixed as the optimum dose.

The data clearly shows that the ADP is more effective than $\mathrm{RDP}$ for removal of $\mathrm{Cu}(\mathrm{II})$ and $\mathrm{Cd}(\mathrm{II})$ ions from aqueous solution. The removal of metal from $\mathrm{Cd}(\mathrm{II})$ and $\mathrm{Cu}$ (II) solutions reached to $98.3 \%$ and $87.3 \%$ at $0.2 \mathrm{~g}$ dosage of ADP adsorbent, whereas $90 \%$ and $65.7 \%$ at $0.5 \mathrm{~g}$ dosage of RDP adsorbent for $\mathrm{Cu}(\mathrm{II})$ and $\mathrm{Cd}(\mathrm{II})$, respectively. Lower $\mathrm{Cd}$ (II) removal may be due to the fact that the adsorption of $\mathrm{Cu}$ (II) was limited to only monolayer adsorption. This is proved by the calculation of correlation coefficient, $R^{2}$ value from Langmuir isotherm.

3.3. Effect of Initial PH. The $\mathrm{pH}$ of the solution affects the surface charge of the adsorbents as well as the degree of ionization and speciation of different pollutants [23]. It is known that metal species $[\mathrm{M}(\mathrm{II})=\mathrm{Cd}(\mathrm{II}), \mathrm{Cu}(\mathrm{II})]$ are present in deionized water in the form of $\mathrm{M}^{+2}, \mathrm{M}(\mathrm{OH})_{2}$, $\mathrm{M}(\mathrm{OH})(\mathrm{S})$, and so forth [24]. It is obvious that the adsorption of $\mathrm{M}$ (II) must be higher in alkaline solution. But at higher $\mathrm{pH}$, the precipitation as $\mathrm{M}(\mathrm{OH})_{2}(\mathrm{~S})$ plays the main role in removing the $\mathrm{M}(\mathrm{II})$ ions. Therefore, all the experiments were conducted at $\mathrm{pH} \leq 8$. Figures $3(\mathrm{a})$ and 3 (b) represent the effect of initial $\mathrm{pH}$ of the solution on the adsorption of $\mathrm{Cu}(\mathrm{II})$ and $\mathrm{Cd}(\mathrm{II})$ onto $0.5 \mathrm{~g}$ RDP and $0.2 \mathrm{gm}$ ADP using $50 \mathrm{mg} / \mathrm{L}$ initial metal ion concentration. The optimum $\mathrm{pH}$ was found to be $\mathrm{pH} 5.8 \pm 0.5$ for both studied adsorbents. The maximum removal of $\mathrm{Cu}(\mathrm{II})$ efficiency was $82.16 \%$ and $96.67 \%$ for RDP and ADP, respectively, and the maximum removal of $\mathrm{Cd}(\mathrm{II})$ efficiency was $41.75 \%$ and $60.00 \%$ for RDP and ADP, respectively. This may be attributed to the competition between the hydrogen and metal ions on the sorption sites, at low $\mathrm{pH}$ values. At $\mathrm{pH}$ values higher than 6.0 insoluble, metal hydroxide ( $\mathrm{Cd}$ or $\mathrm{Cu}$ ) starts precipitating from the solutions making true sorption studies impossible [24]. Consequently, the working $\mathrm{pH}$ value for copper removal onto RDP and ADP was chosen as $5.8 \pm$ 0.5 , and the other adsorption experiments were performed at this $\mathrm{pH}$ value.

3.4. Effect of Contact Time. Effect of contact time for the removal of $\mathrm{Cd}(\mathrm{II})$ and $\mathrm{Cu}(\mathrm{II})$ by $0.5 \mathrm{~g}$ RDP and $0.2 \mathrm{~g}$ ADP from aqueous solution is shown in Figures $4(\mathrm{a})$ and $4(\mathrm{~b})$. There was a rapid adsorption of $\mathrm{Cd}$ (II) and $\mathrm{Cu}$ (II) in the first $20 \mathrm{~min}$, and, thereafter, the rate of adsorption become slower; this is due to decreased or lesser number of active sites [25]. The maximum removal efficiency of Cd(II) was $(86 \%$ and $97.5 \%)$, and it was attained in about 65 and $50 \mathrm{~min}$ for RDP and ADP, respectively, and the maximum removal efficiency of $\mathrm{Cu}(\mathrm{II})$ was $59 \%$ and $82 \%$ for RDP and ADP, respectively.

3.5. Effect of Initial Metal Ion Concentration. The adsorption experiments were carried out with metal ions concentrations of $10,25,50,75,100$, and $110 \mathrm{mg} / \mathrm{L}$ with a constant raw and activated date pits amounts of 0.5 and $0.2 \mathrm{~g}$, respectively, contact time $60 \mathrm{~min}$ and $\mathrm{pH} 5.8 \pm 0.5$. The amount adsorbed per unit mass of cadmium and copper ions at different concentrations is shown in Figures 5(a) and 5(b). As in Figures 5(a) and 5(b) is shown the amount adsorbed per unit, mass $q_{e}$ increased with an increase in metal ions concentration.

There are various possible interaction effects between different species in solution and, in particular, potential interactions on the surface depending on the adsorption 


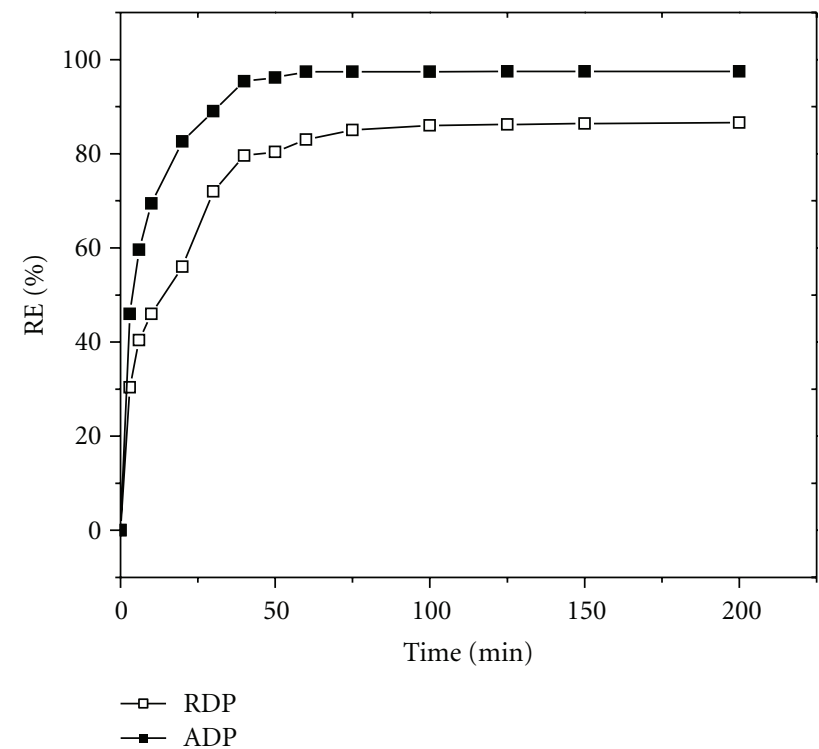

(a)

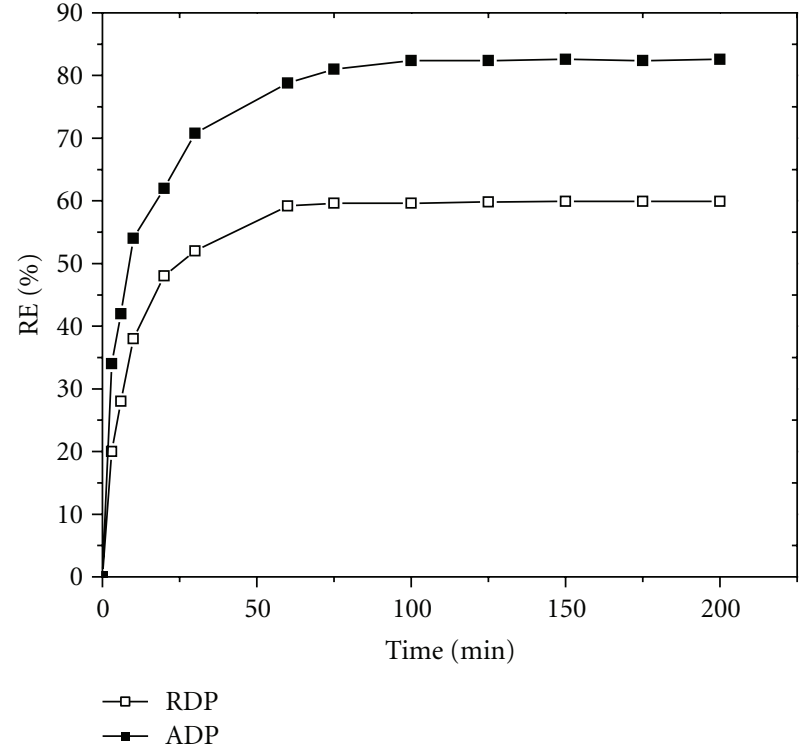

(b)

FIgURE 4: (a) Effect of the contact time on adsorption of $\mathrm{Cu}$ (II) by selected adsorbent at $\mathrm{pH}=5.8 \pm 0.5$, adsorbent dosage $(0.5 \mathrm{~g}$ RDP and $0.2 \mathrm{~g} \mathrm{ADP}$ ), initial concentration $50 \mathrm{mg} / \mathrm{L}$. (b) Effect of the contact time on adsorption of Cd(II) by selected adsorbent at $\mathrm{pH}=5.8 \pm 0.5$, adsorbent dosage ( $0.5 \mathrm{~g}$ RDP and $0.2 \mathrm{~g} \mathrm{ADP})$, initial concentration $50 \mathrm{mg} / \mathrm{L}$.

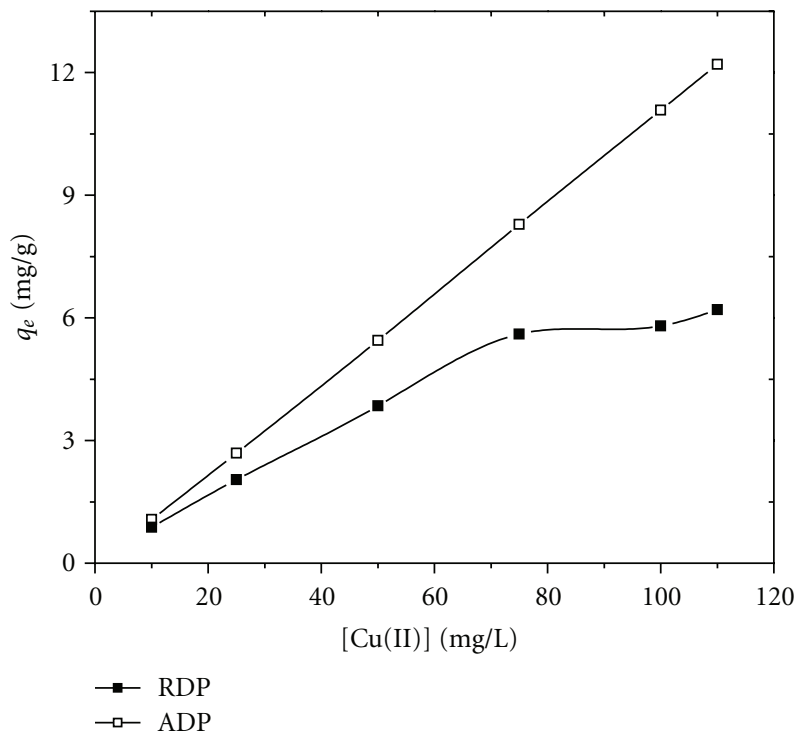

(a)

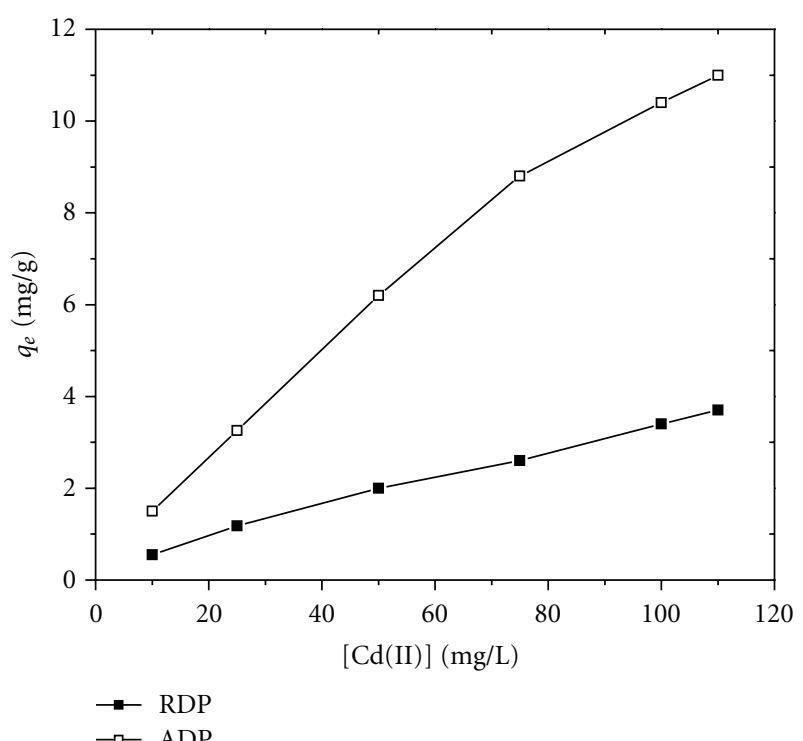

(b)

FIGURE 5: Effect of initial concentration on the adsorption of metal ions by selected adsorbent at $\mathrm{pH}=5.8 \pm 0.5$, adsorbent dosage $(0.5 \mathrm{~g}$ RDP and $0.2 \mathrm{~g} \mathrm{ADP}), 60 \mathrm{~min}$ contact time.

mechanism. Factors that affect the binding sites (e.g., functional groups, structures, and surface properties), the properties of the adsorbates (e.g., concentration, ionic nature, or standard redox potential), and the solution chemistry (e.g., $\mathrm{pH}$ and ionic strength). In the context of adsorption, a number of properties have been suggested for use in the ordering of affinity rank, including ionic radius and solubility product constant as hydroxides [26], pulling electronegativity and standard reduction potential [27], first hydrolysis constant [28].

The properties may play an important role in metal ion adsorbent interaction, but can only partly explain highor low-adsorption capacities. The atomic weight of $\mathrm{Cd}(\mathrm{II})$ is highest as compared to $\mathrm{Cu}(\mathrm{II})$, and the ionic radius of $\mathrm{Cd}(\mathrm{II})$ is highest as compared to $\mathrm{Cu}(\mathrm{II})$. Both of the tested adsorbents showed higher adsorption capacity for 
TABLE 1: Isotherm parameters for adsorption of $\mathrm{Cu}(\mathrm{II})$ onto selected adsorbents, RDP and ADP.

\begin{tabular}{lcccccccccc}
\hline \multirow{2}{*}{ Adsorbent } & \multicolumn{4}{c}{ Langmuir model } & \multicolumn{4}{c}{ Freundlich model } & \multicolumn{4}{c}{ Dubinin-Radushkevich (D-R) model } \\
& $Q_{m}$ & $K_{L}$ & $R_{L}$ & $R^{2}$ & $n$ & $K_{f}$ & $R^{2}$ & $X_{m}$ & $\lambda(10)^{7}$ & $R^{2}$ \\
\hline RDP & 7.40 & 0.103 & $0.08-0.49$ & 0.990 & 1.19 & 0.90 & 0.991 & 1.10 & 0.19 \\
ADP & 33.44 & 0.045 & $0.17-0.69$ & 0.970 & 1.86 & 1.50 & 0.999 & 1.98 & 0.877 \\
\hline
\end{tabular}

TABLE 2: Isotherm parameters for adsorption of Cd(II) onto selected adsorbents, RDP and ADP.

\begin{tabular}{lccccccccr}
\hline \multirow{2}{*}{ Adsorbent } & \multicolumn{4}{c}{ Langmuir model } & \multicolumn{3}{c}{ Freundlich model } & \multicolumn{4}{c}{ Dubinin-Radushkevich (D-R) model } \\
& $Q_{m}$ & $K_{L}$ & $R_{L}$ & $R^{2}$ & $n$ & $K_{f}$ & $R^{2}$ & $X_{m}$ & $\lambda(10)^{7}$ \\
\hline RDP & 6.02 & 0.019 & $0.32-0.84$ & 0.963 & 1.49 & 0.203 & 0.999 & 0.75 & 0.14 \\
ADP & 17.24 & 0.032 & $0.22-0.76$ & 0.985 & 1.51 & 0.82 & 0.997 & 1.04 & 0.14 \\
\hline
\end{tabular}

$\mathrm{Cu}(\mathrm{II})$ ions as compared to $\mathrm{Cd}(\mathrm{II})$. However, the adsorption order is found to be in the order of increasing molecular weight and ionic radius, for example, $\mathrm{Cu}(\mathrm{II})>\mathrm{Cd}(\mathrm{II})$. The increase in initial metal ion concentrations also enhances the interaction between the metal ions in the aqueous phase and the adsorbents. Therefore, an increase in the initial metal ion concentrations enhances the adsorption uptake of $\mathrm{Cu}$ (II) and Cd(II) onto RDP and ADP as shown in Figures 5(a) and 5(b).

3.6. Adsorption Equilibrium Study. The purpose of the adsorption isotherm is to relate the adsorbate concentration in the bulk solution and the adsorbed amount at the interface. The analysis of the isotherm data is important to develop an equation which accurately represents the results and which could be used for the design purpose.

Langmuir and Freundlich; Temkin and DubininRadushkevich (D-R) isotherm models were used to describe the adsorption equilibrium. Experimental isotherm data were conducted at an equilibrium time of $200 \mathrm{~min}$ for different dosages of adsorbate.

3.6.1. Langmuir Isotherm. The Langmuir adsorption isotherm is based on the assumption that all sites possess equal affinity for the adsorbate. It may be represented in the linear form as follows [29]:

$$
\frac{C_{e}}{q_{e}}=\frac{1}{K_{L} Q_{m}}+\frac{C_{e}}{Q_{m}},
$$

where $C_{e}$ is the equilibrium concentration $\left(\mathrm{mg} / \mathrm{L}^{1}\right), q_{e}$ is the amount adsorbed at equilibrium $(\mathrm{mg} / \mathrm{gm})$, and $Q_{m}$ and $K_{L}$ are Langmuir constants related to adsorption capacity $(\mathrm{mg} / \mathrm{gm}$ and energy of adsorption capacity $(\mathrm{L} / \mathrm{mgm})$, respectively. The linear plots of $C_{e} / q_{e}$ versus $C_{e}$ suggest the applicability of the Langmuir isotherms. The values of $Q_{m}$ and $K_{L}$ were determined from slope and intercepts of the plots for two heavy metal ions [Cu(II) and $\mathrm{Cd}(\mathrm{II})]$ and are presented in Tables 1 and 2 and Figures 6 and 7. The shape of the Langmuir isotherm was investigated by the dimensionless constant separation term $\left(R_{L}\right)$ to determine high-affinity adsorption [30]. $R_{L}$ was calculated as follows:

$$
R_{L}=\frac{1}{\left(1+K_{L} C_{o}\right)},
$$

where $C_{o}$ is the initial metal ion concentration $(\mathrm{mg} / \mathrm{L}) . R_{L}$ indicates the type of isotherm to be irreversible $\left(R_{L}=0\right)$, favorable $\left(0<R_{L}<1\right)$, linear $\left(R_{L}=1\right)$, (or) unfavorable $\left(R_{L}>1\right)$. In the present investigation, the $R_{L}$ values for RDP and ADP were less than one for two metals, showing favorable adsorption.

3.6.2. Freundlich Isotherm. Freundlich isotherm is an empirical equation. This equation is one among the most widely used isotherms for the description of adsorption equilibrium. Freundlich isotherm is capable of describing the adsorption of organic and inorganic compounds on a wide variety of adsorbents. The Freundlich equation form could be written as follows [31]:

$$
\log q_{e}=\log k_{f}+\frac{1}{n} \log C_{e}
$$

The constants $K_{f}$ and $1 / n$ were calculated from the intercept and slope of the plot of $\log q_{e}$ versus $\log C_{e}$ as in Figures 8 and 9, and the results were tabulated in Tables 1 and 2. Where $K_{f}$ and $n$ are the Freundlich constants related to the adsorption capacity and adsorption intensity. The values of $n$ were greater than one indicating the favorable adsorption.

3.6.3. Dubinin-Radushkevich (D-R) Isotherm. The DubininRadushkevich (D-R) isotherm approach assumes that there is a surface area where the adsorption energy, is homogeneous [32]. The D-R isotherm has the form:

$$
\ln q_{e}=\ln X_{m}-\lambda €^{2},
$$

where $X_{m}$ represents the maximum sorption capacity of the sorbent, $\lambda$ is a constant related to sorption energy, and $€$ Polanyi sorption potential can be expressed as

$$
€=R T \ln \left(1+\frac{1}{C_{e}}\right) .
$$

The Polanyi adsorption theory postulates [33] fixed volume of sorption site close to sorbent surface and existence of sorption potential over these site. The sorption potential is related to an excess of sorption energy over the condensation energy and is independent of temperature. A plot of $\ln q_{e}$ versus $€^{2}$ gave a straight line, from which values of $X_{m}$ and $\lambda$ 


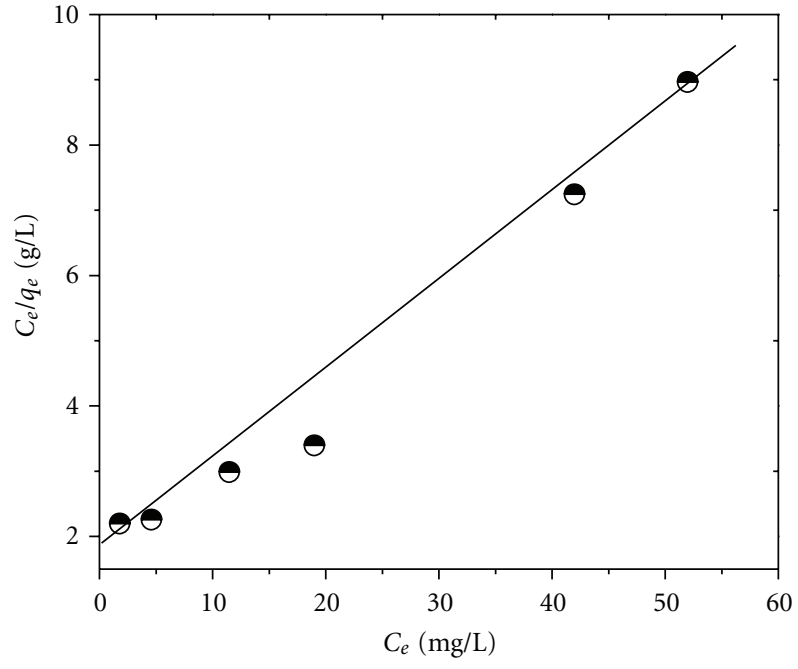

$\ominus$ RDP

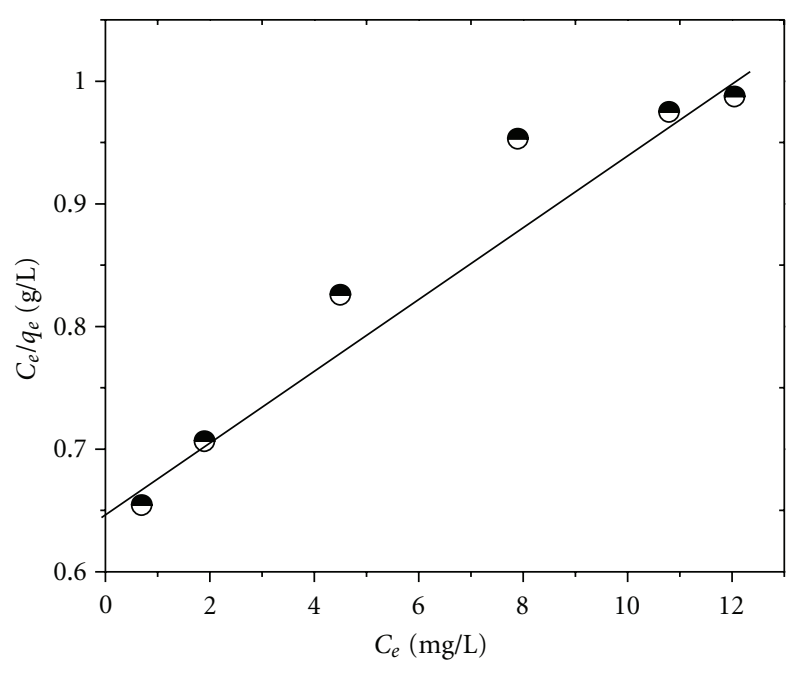

(b)

FIGURE 6: Langmuir isotherm plot for adsorption of $\mathrm{Cu}$ (II) onto selected adsorbent.

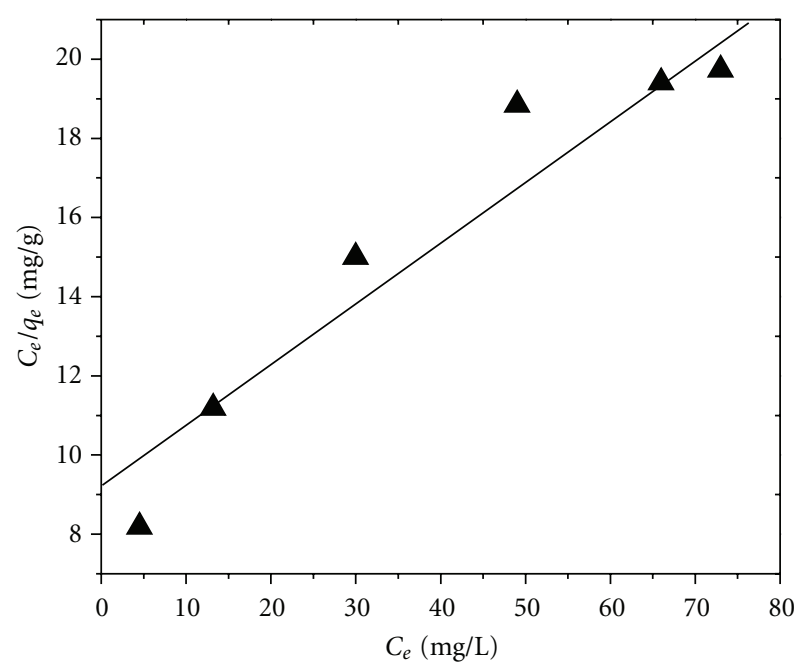

$\triangle \mathrm{RDP}$

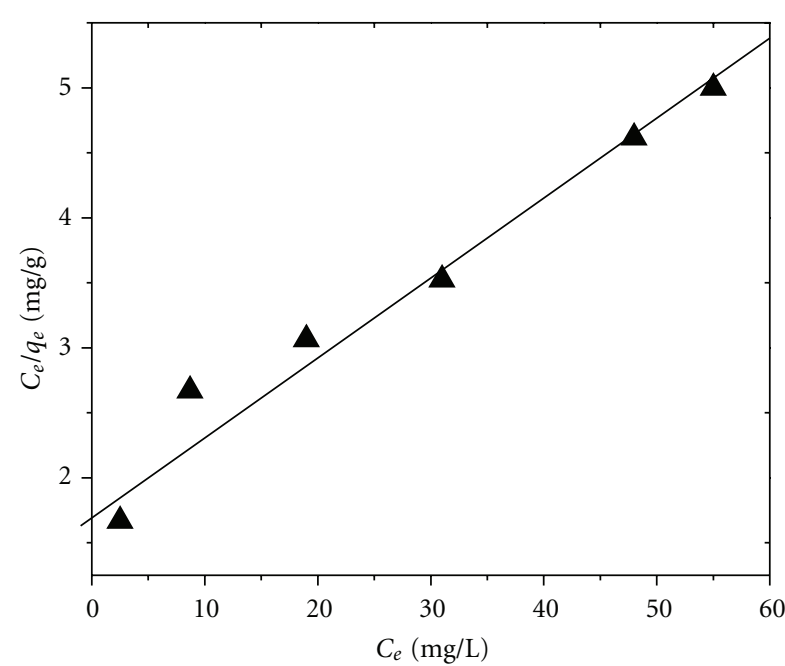

$\triangle \mathrm{ADP}$

(a)

(b)

FIGURE 7: Langmuir isotherm plot for adsorption of Cd(II) onto selected adsorbent.

for $\mathrm{Cu}(\mathrm{II})$ and $\mathrm{Cd}(\mathrm{II})$ onto RDP and $\mathrm{ADP}$ were evaluated in Tables 1 and 2.

The isotherm constants were determined from linear isotherm graphs for each of the isotherm equations tested. The values of the isotherm constants with the correlation coefficients are given in Tables 1 and 2. The Freundlich equation represents the better fit of experimental data than other isotherm equations.

3.7. Adsorption Kinetic Study. In order to investigate the controlling mechanism of adsorption processes such as mass transfer and chemical reaction, the pseudo-first-order and pseudo-second-order equations are applied to model the kinetics of metal ions adsorption onto RDP and ADP.

3.7.1. Pseudo-First-Order Kinetic Model. Natarajan and Khalaf-as cited by Kannan and Veemaraj proposed a pseudo-first-order kinetic model [34]. The integral form of the model is

$$
\log \left(\frac{C_{o}}{C_{e}}\right)=\left(\frac{k_{1}}{2.303}\right) t
$$

A plot of $\log \left(C_{o} / C_{e}\right)$ versus $t$ gives a linear correlation, from which the values of first-order rate constants $k_{1}$ of 


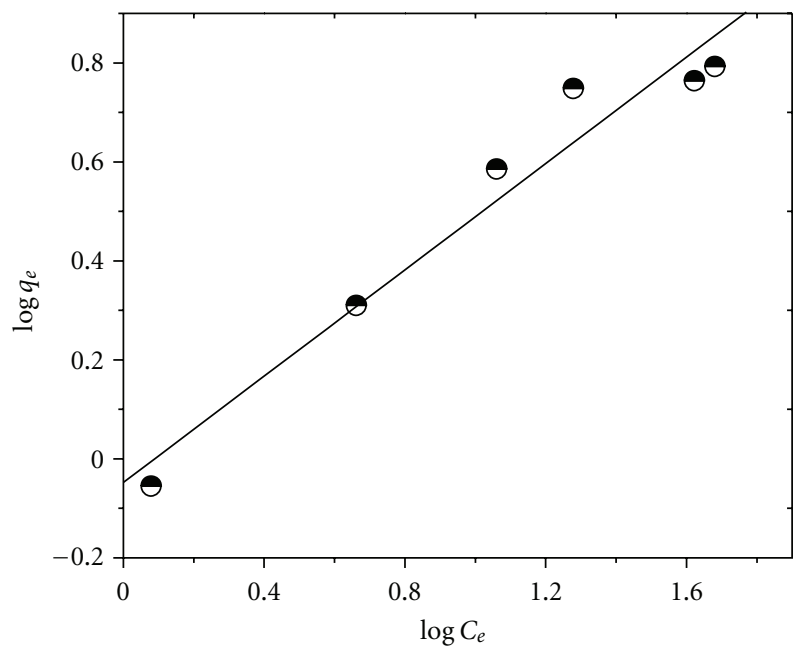

$\ominus \mathrm{RAD}$

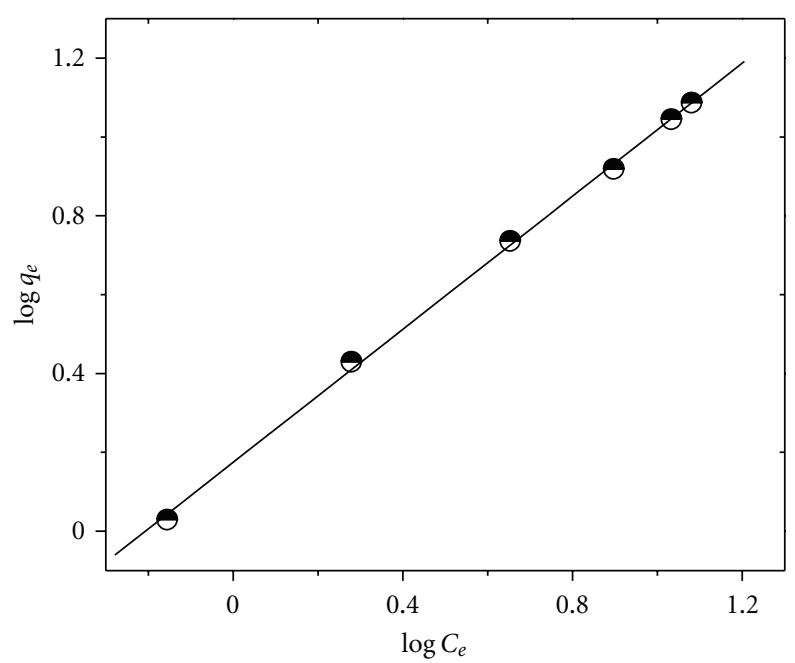

ADP

(a)

(b)

FIGURE 8: Freundlich isotherm plot for adsorption of $\mathrm{Cu}$ (II) onto selected adsorbent.

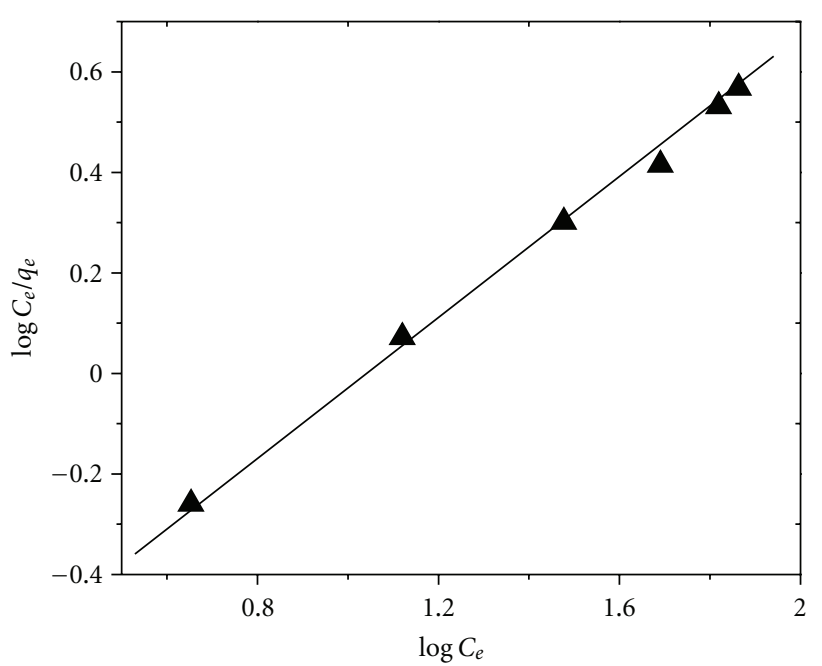

$\Delta \mathrm{RDP}$

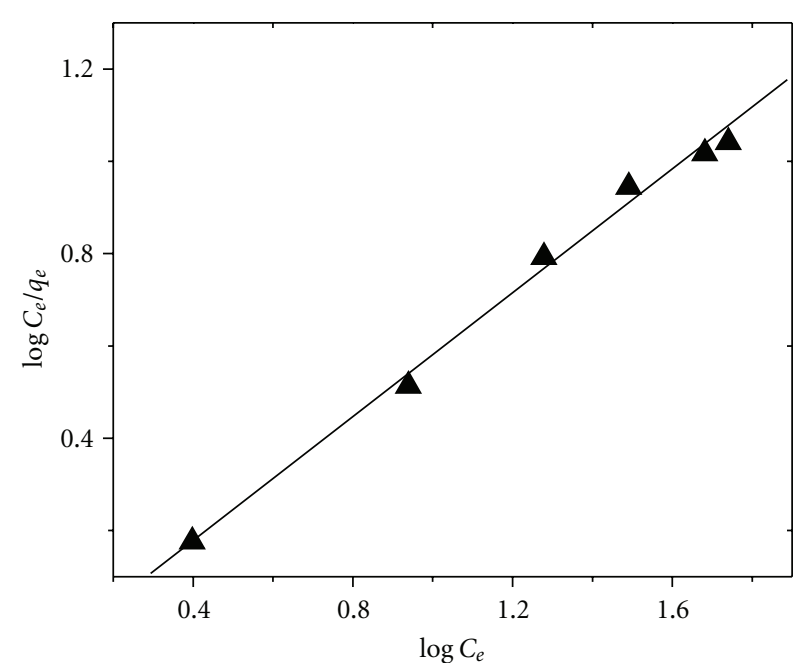

A ADP

(a)

(b)

FIGURE 9: Freundlich isotherm plot for adsorption of Cd(II) onto selected adsorbent.

$\mathrm{Cu}(\mathrm{II})$ and $\mathrm{Cd}(\mathrm{II})$ are calculated and presented in Tables 3 and 4 . This model was successfully applied to describe the kinetics of many adsorption systems.

3.7.2. Pseudo-Second-Order Kinetic Model. The adsorption kinetics may also be described by a pseudo-second-order reaction, which represent in Figures 10(a) and 10(b). The linearized integral form of the model is

$$
\frac{t}{q_{e}}=\frac{1}{K_{2} q_{e}^{2}}+\frac{t}{q_{e}} .
$$

A plot of $t / Q_{t}$ versus $t$ gives a linear relationship (Figures 9(a) and 9(b)), from which $Q_{e}$ and $k_{2}$ were determined from the slope and intercept of the plot, respectively; these values are presented in Tables 3 and 4. For all the systems studied, good correlation coefficients were obtained $\left(R^{2} \approx 1\right)$ by fitting the experimental data to pseudosecond-order kinetics than that for the pseudo-first-order kinetic model. Therefore, the sorption was more favorably by pseudo-second-order kinetic model, which was based on the assumption that the rate limiting step may be chemisorptions involving valences forces through sharing or exchange of electrons between sorbent and sorbate [35].

3.8. Comparison of Metal Ions Removal with Different Adsorbents Reported in the Literature. The adsorption capacities 
TABLE 3: The kinetics constants for the adsorption of $\mathrm{Cu}$ (II) onto RDP and ADP, (initial concentration of $\mathrm{Cu}(\mathrm{II})=50 \mathrm{mg} / \mathrm{L}$ ).

\begin{tabular}{|c|c|c|c|c|}
\hline \multirow{2}{*}{ Adsorbents } & \multicolumn{2}{|c|}{ Pseudo-first-order kinetics } & \multicolumn{2}{|c|}{ Pseudo-second-order kinetics } \\
\hline & $k_{1}, \min ^{-1}$ & $R^{2}$ & $k_{2}, \operatorname{gm}(\mathrm{mg} \min )^{-1}$ & $R^{2}$ \\
\hline $\mathrm{RDP}$ & $4.86 \times 10^{-3}$ & 0.923 & 0.097 & 0.998 \\
\hline $\mathrm{ADP}$ & 0.017 & 0.778 & 0.131 & 0.999 \\
\hline
\end{tabular}

TABLE 4: The kinetics constants for the adsorption of Cd(II) onto RDP and ADP, (initial concentration of Cd(II) $=50 \mathrm{mg} / \mathrm{L}$ ).

\begin{tabular}{|c|c|c|c|c|}
\hline \multirow{2}{*}{ Adsorbents } & \multicolumn{2}{|c|}{ Pseudo-first-order kinetics } & \multicolumn{2}{|c|}{ Pseudo-second-order kinetics } \\
\hline & $k_{1}, \min ^{-1}$ & $R^{2}$ & $k_{2}, \mathrm{~g}(\mathrm{mg} \min )^{-1}$ & $R^{2}$ \\
\hline RDP & $3.45 \times 10^{-3}$ & 0.763 & 0.018 & 0.999 \\
\hline $\mathrm{ADP}$ & $7.23 \times 10^{-3}$ & 0.829 & 0.028 & 0.999 \\
\hline
\end{tabular}

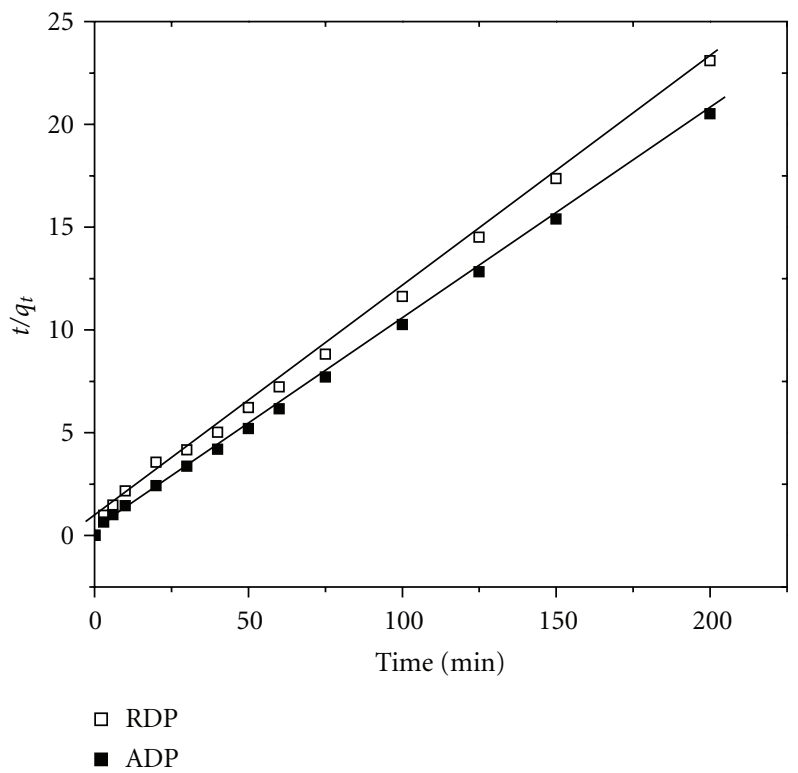

(a)

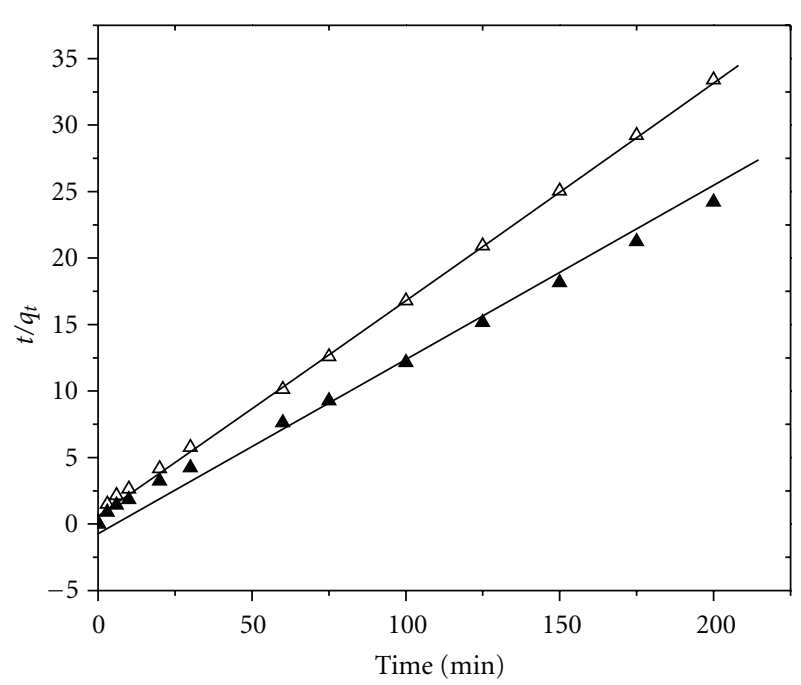

$\triangle \mathrm{RDP}$

\ ADP

(b)

Figure 10: Pseudo-second-order plot for adsorption of (a) Cu(II) and (b) Cd(II) onto RDP and ADP.

of the adsorbents for the removal of both ions have been compared with those of other adsorbents reported in the literature, and the values of adsorption capacities have been presented in Table 5. The values are reported in the form of monolayer adsorption capacity. The experimental data of the present investigations are higher than other reported values in some cases. The adsorption capacity varies, and it depends on the characteristics of the individual adsorbent and the initial concentration of the adsorbate. However, the present experiments are conducted to find the technical applicability of the low-cost adsorbents to treat $\mathrm{Cu}$ (II) and $\mathrm{Cd}(\mathrm{II})$.

\section{Conclusion}

Raw date pits (RDP) and an activated carbon prepared from date pits (ADP) have been used as adsorbents for the removal of copper(II) and Cd(II) from wastewater. Adsorption was influenced by various parameters such as initial $\mathrm{pH}$, initial
TABLE 5: Comparison of adsorption capacity of various adsorbents for $\mathrm{Cu}(\mathrm{II})$ and $\mathrm{Cd}(\mathrm{II})$.

\begin{tabular}{lccc}
\hline \multirow{2}{*}{ Adsorbent } & \multicolumn{3}{c}{ Adsorbent capacity (mg/g) } \\
& $\mathrm{Cu}(\mathrm{II})$ & $\mathrm{Cd}(\mathrm{II})$ & Reference \\
\hline Lentinus edodes pellets & - & 78.6 & {$[36]$} \\
Activated pine bark & - & 30.21 & {$[37]$} \\
Black gram husk & - & 39.99 & {$[26]$} \\
Orange peel & 3.19 & - & {$[38]$} \\
Sawdust & 3.12 & - & {$[38]$} \\
Bagasse & 2.89 & - & {$[38]$} \\
Papaya seed & 3.9 & - & {$[39]$} \\
Raw date pits & 7.40 & 6.02 & This study \\
Activated date pits & 33.44 & 17.24 & This study \\
\hline
\end{tabular}

metal ions concentrations, and dose of adsorbents. The maximum uptake of two metals ions occurred at an initial 
$\mathrm{pH}$ of $5.8 \pm 0.5$. Adsorption was increased with increasing dose of adsorbent and decreased with increasing initial metal ions concentrations. The equilibrium time for adsorption of metal ions from aqueous solutions was achieved within 60 min of contact time. The Freundlich adsorption isotherm model was better used to represent the experimental data. The adsorption kinetics fits to pseudo-second-order model. It is important to remark that date pits are very cheap and highly available material; further, they are more effective compared to other some adsorbents. The results obtained in this study show that date pits are a good and effective adsorbent for the removal of heavy metals and could be used in water and wastewater treatment.

\section{References}

[1] S. Sun, L. Wang, and A. Wang, "Adsorption properties of crosslinked carboxymethyl-chitosan resin with $\mathrm{Pb}(\mathrm{II})$ as template ions," Journal of Hazardous Materials, vol. 136, no. 3, pp. 930-937, 2006.

[2] R. R. Bansode, Treatment of organic and inorganic pollutants in municipal wastewater by agricultural by-product based granular activated carbons [M.S. thesis], The Department of Food Science, Louisiana State University and Agricultural and Mechanical College, Baton Rouge, La, USA, 2002.

[3] M. I. Kefala, A. I. Zouboulis, and K. A. Matis, "Biosorption of cadmium ions by Actinomycetes and separation by flotation," Environmental Pollution, vol. 104, no. 2, pp. 283-293, 1999.

[4] K. Prasad, P. Gopikrishna, R. Kala, T. P. Rao, and G. R. K. Naidu, "Solid phase extraction vis-à-vis coprecipitation preconcentration of cadmium and lead from soils onto 5,7dibromoquinoline-8-ol embedded benzophenone and determination by FAAS," Talanta, vol. 69, no. 4, pp. 938-945, 2006.

[5] S. Mohan and G. Sreelakshmi, "Fixed bed column study for heavy metal removal using phosphate treated rice husk," Journal of Hazardous Materials, vol. 153, no. 1-2, pp. 75-82, 2008.

[6] Y. K. Agrawal, P. Shrivastav, and S. K. Menon, "Solvent extraction, separation of uranium (VI) with crown ether," Separation and Purification Technology, vol. 20, no. 2-3, pp. 177-183, 2000.

[7] C. Brach-Papa, B. Coulomb, J. L. Boudenne, V. Cerda, and F. Theraulaz, "Spectrofluorimetric determination of aluminum in drinking waters by sequential injection analysis," Analytica Chimica Acta, vol. 457, no. 2, pp. 311-318, 2002.

[8] P. A. Brown, S. A. Gill, and S. J. Allen, "Metal removal from wastewater using peat," Water Research, vol. 34, no. 16, pp. 3907-3916, 2000.

[9] V. Gopal and K. P. Elango, "Equilibrium, kinetic and thermodynamic studies of adsorption of fluoride onto plaster of Paris," Journal of Hazardous Materials, vol. 141, no. 1, pp. 98105, 2007.

[10] M. I. Kandah, "Zinc and cadmium adsorption on low-grade phosphate," Separation and Purification Technology, vol. 35, no. 1, pp. 61-70, 2004.

[11] M. Sharma, V. K. Gupta, V. K. Saini, C. K. Jain, and I. Ali, "Removal of cadmium and nickel from wastewater using bagasse fly ash—a sugar industry waste," Water Research, vol. 37, no. 16, pp. 4038-4044, 2003.

[12] E. Demirbas, M. Kobya, S. Tncel, and S. Sencan, "Determination of kinetic and equilibrium parameters of the batch adsorption of $\mathrm{Co}(\mathrm{II}), \mathrm{Cr}(\mathrm{III})$ and $\mathrm{Ni}(\mathrm{II})$ onto coir pith," Bioresource Technology, vol. 84, no. 3, pp. 291-297, 2002.

[13] H. Parab, S. Joshi, N. Shenoy, A. Lali, U. S. Sarma, and M. Sudersanan, "Determination of kinetic and equilibrium parameters of the batch adsorption of $\mathrm{Co}(\mathrm{II}), \mathrm{Cr}(\mathrm{III})$ and Ni(II) onto coir pith," Process Biochemistry, vol. 41, no. 3, pp. 609-615, 2006.

[14] J. Qu, "Research progress of novel adsorption processes in water purification: a review," Journal of Environmental Sciences, vol. 20, no. 1, pp. 1-13, 2008.

[15] T. Lee, J. W. Park, and J. H. Lee, "Waste green sands as reactive media for the removal of zinc from water," Chemosphere, vol. 56, no. 6, pp. 571-581, 2004.

[16] H. N. Bhatti, B. Mumtaz, M. A. Hanif, and R. Nadeem, "Removal of $\mathrm{Zn}$ (II) ions from aqueous solution using Moringa oleifera Lam. (horseradish tree) biomass," Process Biochemistry, vol. 42, no. 4, pp. 547-553, 2007.

[17] K. O. Olayinka, B. I. Alo, and T. Adu, "Sorption of heavy metals from electroplating effluents by low-cost adsorbents II: use of waste tea, coconut shell and coconut husk," Journal of Applied Sciences, vol. 7, no. 16, pp. 2307-2313, 2007.

[18] R. C. Ansal and M. Goyal, Activated Carbon Adsorption, Taylor \& Francis, London, UK, 2005.

[19] R. Malik, D. S. Ramteke, and S. R. Wate, "Adsorption of malachite green on groundnut shell waste based powdered activated carbon," Waste Management, vol. 27, no. 9, pp. 11291138, 2007.

[20] W. B. Wan Nik, M. M. Rahman, A. M. Yusof, F. N. Ani, and C. N. Che Adnan, "Production of activated carbon from palm oil shell waste and its adsorption characteristics," in Proceedings of the 1st International Conference on Natural Resources, Engineering and Technology, pp. 646-654, Putrajaya, Malaysia, July 2006.

[21] F. Li, P. Du, W. Chen, and S. Zhang, "Preparation of silicasupported porous sorbent for heavy metal ions removal in wastewater treatment by organic-inorganic hybridization combined with sucrose and polyethylene glycol imprinting," Analytica Chimica Acta, vol. 585, no. 2, pp. 211-218, 2007.

[22] I. D. Mall, V. C. Srivastava, and N. K. Agarwal, "Removal of orange- $\mathrm{G}$ and methyl violet dyes by adsorption onto bagasse fly ash-kinetic study and equilibrium isotherm analyses," Dyes and Pigments, vol. 69, no. 3, pp. 210-223, 2006.

[23] H. A. Elliott and C. P. Huang, "Adsorption characteristic of some $\mathrm{Cu}$ (II) complexes on alumina silicates," Water Research, vol. 15 , no. 7, pp. 849-854, 1981.

[24] V. L. Snoeyink and D. Jenkins, Water Chemistry, John Wiley \& Sons, New York, NY, USA, 1980.

[25] N. Kannan and A. Xavier, "New composite mixed adsorbents for the removal of acetic acid by adsorption from aqueous solutions a comparative study," Toxicological and Environmental Chemistry, vol. 79, no. 1-2, pp. 95-107, 2001.

[26] A. Saeed, M. Iqbal, and M. W. Akhtar, "Removal and recovery of lead(II) from single and multimetal (Cd, $\mathrm{Cu}, \mathrm{Ni}, \mathrm{Zn}$ ) solutions by crop milling waste (black gram husk)," Journal of Hazardous Materials, vol. 117, no. 1, pp. 65-73, 2005.

[27] G. McKay and J. F. Poter, "Equilibrium parameter for the sorption of copper, cadmium and zinic ion onto peat," Journal of Chemical Technology and Biotechnology, vol. 69, no. 3, pp. 309-320, 1997.

[28] F. Pagnanelli, A. Esposito, L. Toro, and F. Vegliò, "Metal speciation and $\mathrm{pH}$ effect on $\mathrm{Pb}, \mathrm{Cu}, \mathrm{Zn}$ and $\mathrm{Cd}$ biosorption onto Sphaerotilus natans: langmuir-type empirical model," Water Research, vol. 37, no. 3, pp. 627-633, 2003. 
[29] I. Langmuir, "The constitution and fundamental properties of solids and liquids. Part I. Solids," The Journal of the American Chemical Society, vol. 38, no. 2, pp. 2221-2295, 1916.

[30] P. K. Malik, "Use of activated carbons prepared from sawdust and rice-husk for adsoprtion of acid dyes: a case study of acid yellow 36," Dyes and Pigments, vol. 56, no. 3, pp. 239-249, 2003.

[31] M. H. Kalavathy, T. Karthikeyan, S. Rajgopal, and L. R. Miranda, "Kinetic and isotherm studies of $\mathrm{Cu}(\mathrm{II})$ adsorption onto $\mathrm{H}_{3} \mathrm{PO}_{4}$-activated rubber wood sawdust," Journal of Colloid and Interface Science, vol. 292, no. 2, pp. 354-362, 2005.

[32] M. M. Dubinin and L. V. Radushkevich, "Equation of the characteristic curve of activated charcoal," Proceedings of the Academy of Sciences, Physical Chemistry Section, USSR, vol. 55, pp. 331-333, 1947.

[33] M. Polanyi, "Section III.- - theories of the adsorption of gases. A general survey and some additional remarks. Introductory paper to section III," Transactions of the Faraday Society, vol. 28, pp. 316-333, 1932.

[34] N. Kannan and T. Veemaraj, "Removal of lead(II) ions by adsorption onto bamboo dust and commercial activated carbons-a comparative study," E-Journal of Chemistry, vol. 6, no. 1, pp. 247-256, 2009.

[35] E. Bulut, M. Özacar, and İ. A. Şengil, "Equilibrium and kinetic data and process design for adsorption of Congo Red onto bentonite," Journal of Hazardous Materials, vol. 154, no. 1-3, pp. 613-622, 2008.

[36] G. Bayramoğlu and M. Y. Arica, "Removal of heavy mercury(II), cadmium(II) and zinc(II) metal ions by live and heat inactivated Lentinus edodes pellets," Chemical Engineering Journal, vol. 143, no. 1-3, pp. 133-140, 2008.

[37] M. E. Argun and S. Dursun, "Cadmium removal using activated pine bark," Journal of International Environmental Application and Science, vol. 3, no. 1, pp. 37-42, 2008.

[38] H. Ahsan, I. Nazrut, I. Anarul, and A. M. fiqul, "Removal of copper from aqueous solution using orange, sawdust and bagasse," Pakistan Journal of Analytical and Environmental Chemistry, vol. 8, no. 1-2, pp. 21-25, 2007.

[39] A. J. Ahamed and A. S. Begum, "Adsorption of copper from aqueous solution using low cost adsorption," Archives of Applied Science Research, vol. 4, no. 3, pp. 1532-1539, 2012. 


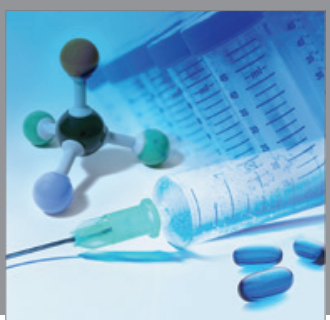

International Journal of

Medicinal Chemistry

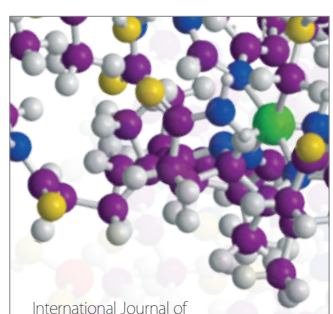

Carbohydrate Chemistry

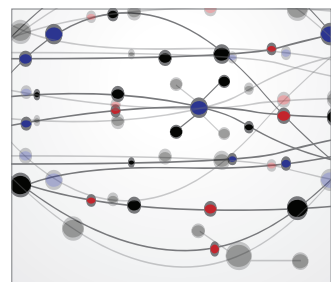

The Scientific World Journal
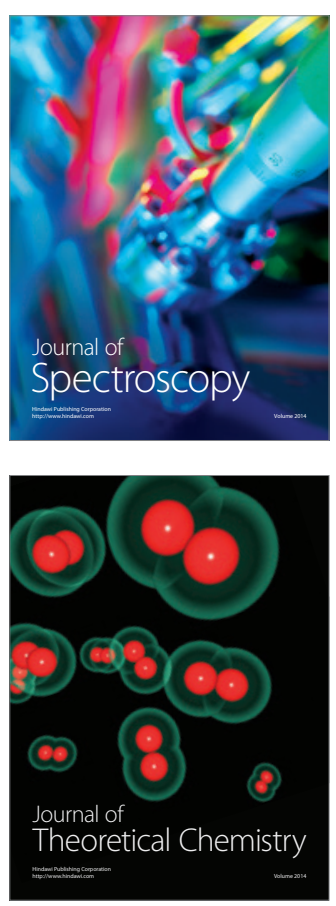
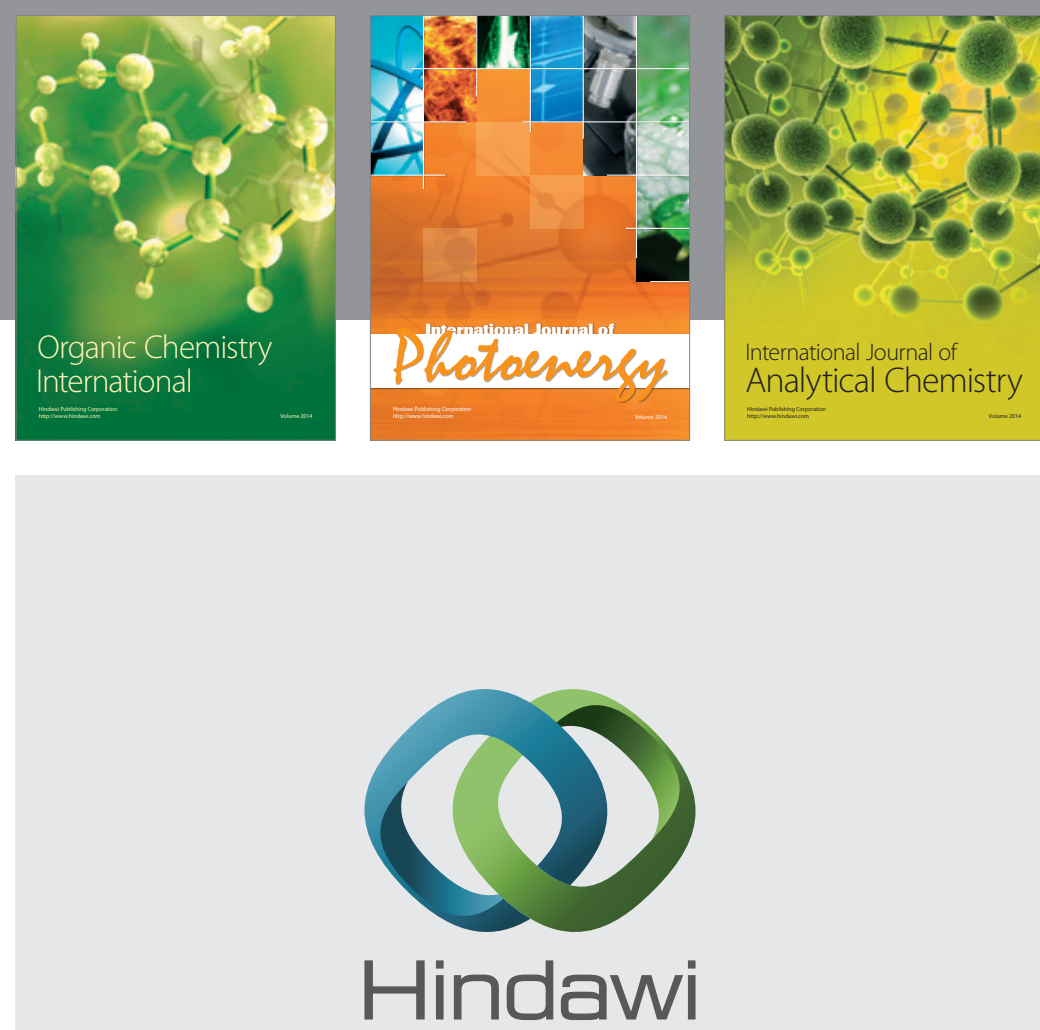

Submit your manuscripts at

http://www.hindawi.com
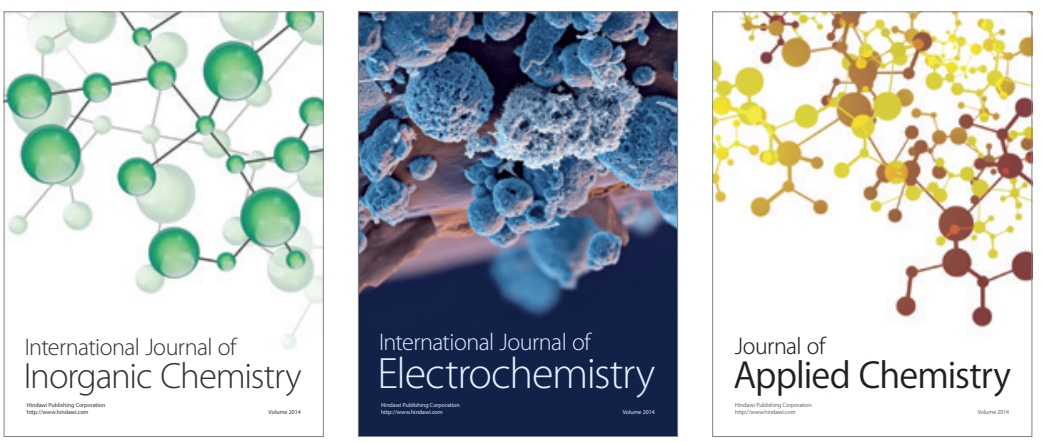

Journal of

Applied Chemistry
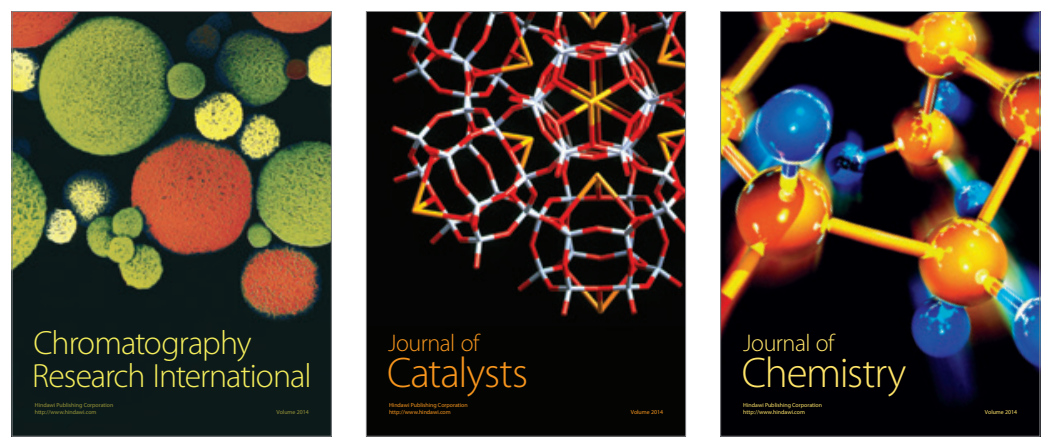
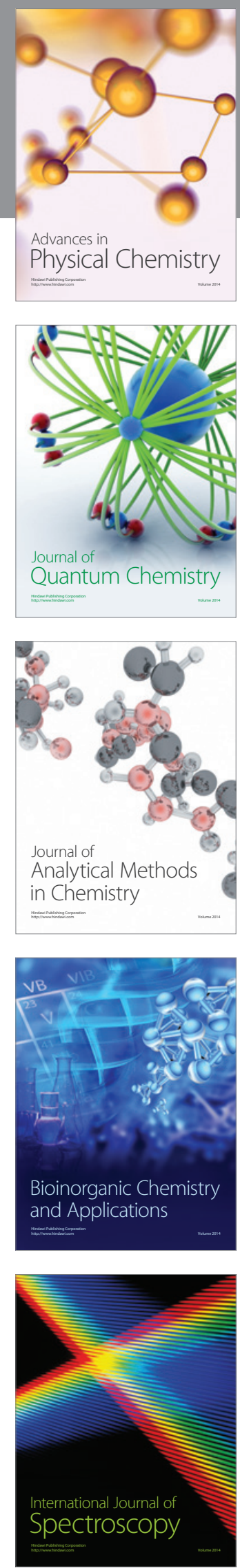